\title{
Palliative radiation for bone metastases from hepatocellular carcinoma: practice patterns and the amount of remaining life spent receiving treatment
}

\author{
Ryan K. Schmid ${ }^{1}$, Candice A. Johnstone ${ }^{2}$, Jared R. Robbins ${ }^{3} \wedge$ \\ ${ }^{1}$ Department of Radiology, Duke University, Durham, NC, USA; ${ }^{2}$ Department of Radiation Oncology, Medical College of Wisconsin, Milwaukee, \\ WI, USA; ${ }^{3}$ Department of Radiation Oncology, University of Arizona College of Medicine-Tucson, Tucson, AZ, USA \\ Contributions: (I) Conception and design: All authors; (II) Administrative support: All authors; (III) Provision of study materials or patients: All \\ authors; (IV) Collection and assembly of data: JR Robbins, RK Schmid; (V) Data analysis and interpretation: All authors; (VI) Manuscript writing: All \\ authors; (VII) Final approval of manuscript: All authors. \\ Correspondence to: Jared R. Robbins, MD. Department of Radiation Oncology, University of Arizona College of Medicine-Tucson, 3838 N. Campbell \\ Ave, Building \#2, Tucson, AZ 85718, USA. Email: jrobbins@email.arizona.edu.
}

\begin{abstract}
Background: Palliative radiation therapy (RT) for bone metastases (BMs) is a common practice. Wide variation exists in clinically used dose schema despite numerous studies demonstrating palliative equipoise between single and multifraction courses. We hypothesize that fraction scheme for palliating BMs for hepatocellular carcinoma (HCC) significantly affects how patients spend their remaining time.

Methods: Patients with osseous HCC metastases who received RT were identified from the National Cancer Database [2004-2013]. The percentage of remaining life spent receiving radiation therapy (PRLSRT) and the number of incomplete RT courses were calculated. Kaplan-Meier analysis and Cox proportional hazards models were used to evaluate trends and predictors.

Results: A total of 1,331 patients met the inclusion criteria. Median overall survival (OS) was 3.3 months. Just 49 (3.7\%) of patients received single fraction RT and 34\% received $>10$ fractions. The mean and median PRLSRT were as follows: 1 fraction (8.9\% and 3.0\%), 2-5 fractions (32.9\% and 24.3\%), 6-10 fractions (27.2\% and $15.9 \%$ ), and $>10$ fractions $(24.1 \%$ and $14.4 \%)$. Of the patients with PRLSRT >50\%, 99.6\% received multifraction RT. The proportion of incomplete RT courses increased as fraction size decreased from $17.6 \%$ with 4 Gy to $34 \%$ with 2 Gy.

Conclusions: Single fraction palliative RT is vastly underutilized despite no additional palliative benefit with multifraction RT. PRLSRT significantly increased with multifraction RT. In the palliative treatment of painful BMs from HCC, single fraction treatment reduces time spent receiving radiation treatments and maximizes the number of patients who complete the prescribed treatment.
\end{abstract}

Keywords: Palliative radiation therapy; bone metastases (BMs); hepatocellular carcinoma (HCC)

Submitted Sep 16, 2021. Accepted for publication Jan 14, 2022.

doi: 10.21037/apm-21-2657

View this article at: https://dx.doi.org/10.21037/apm-21-2657

^ ORCID: 0000-0003-1724-5242. 


\section{Introduction}

As advances in cancer treatment prolong survival, bone metastases (BMs) from underlying malignancy are becoming an increasingly prevalent source of pain leading to significant deterioration in quality of life (1-4). Bone pain is a leading cause of morbidity in patients with cancer, and BMs represent the leading cause for bone pain (3). Complications from BMs include hypercalcemia, decreased function and quality of life, pathological fractures, as well as neurovascular compression $(3,5)$. Indications for the treatment of BMs include pain, skeletal functional impairment, as well as pathological fractures (5).

The diagnosis of hepatocellular carcinoma (HCC) confers a poor prognosis with a 5 -year survival of $31 \%$ for those with localized disease and $2 \%$ for metastatic disease (6). Most patients are diagnosed at advanced stages and receive palliative treatments (7). BMs in HCC are estimated at $6-33 \%$, however a more recent study has estimated as high as $32.9 \%$ with annual incidence of $6.4 \%(8,9)$. radiation therapy (RT) is an effective means for the palliation of pain caused by BMs with rates of pain relief as high as 79\% (10-12). Many studies investigating fractionation schemes of RT for palliation of BMs have demonstrated no difference in pain outcomes, the development of spinal cord compression, or pathologic fracture between those treated with single or hypofractionated treatments versus more protracted radiation courses (13-20). Despite this data there remain a wide number of treatment regimens in use. Current american society for radiation oncology (ASTRO) approved dose-fractionation schema include: $8 \mathrm{~Gy} / 1 \mathrm{Fx}, 20 \mathrm{~Gy} / 5$ Fx, 24 Gy/6 Fx and 30 Gy/10 Fx (21). A Choosing Wisely recommendation posits that single fraction RT should be used for all uncomplicated BMs (22).

The purpose of this study was to investigate practice patterns in patients treated with palliative RT for BMs from HCC. The hypothesis is that patients undergoing longcourse palliative regimens spend a greater portion of their remaining life receiving radiation treatments and higher rates of incomplete courses compared to those receiving single fraction treatments. Due to the poor prognosis of HCC, maximizing quality of life and minimizing travel and time receiving RT should be of the utmost importance. Spending a significant portion of one's remaining time receiving daily palliative radiation treatments may detract from the anticipated benefit of the radiation and patient overall quality of life. We present the following article in accordance with the STROBE reporting checklist (available at https://apm. amegroups.com/article/view/10.21037/apm-21-2657/rc).

\section{Methods}

\section{Study design}

The study was conducted in accordance with the Declaration of Helsinki (as revised in 2013). The National Cancer Database (NCDB) was queried to identify patients with HCC metastases to the bone who received RT using International Classification of Diseases-Third revision (ICD-3) histology codes 8170-8175 and the codes for radiation treatment volume for bone (24-28, 37, 38, and 40) between 2004 and 2013. Patients with missing or unknown radiation dose data, and lacking follow-up were excluded. The duration of time spent receiving radiation treatment was identified and used to calculate percentage of remaining life spent receiving radiation therapy (PRLSRT):

$$
\operatorname{PRLSRT}(\%)=100 \frac{\text { Elapsed days of RT }}{\text { Elapsed days from start of RT to death }}
$$

An exploratory analysis was performed to determine the hypothetical percentage of remaining life spent receiving radiation therapy $\left(\mathrm{H}_{\mathrm{PRLSRT}}\right)$ had the patients in the multifraction subset received single fraction RT instead:

$$
\mathrm{H}_{\text {PRLSRT }}(\%)=100 \frac{\text { Hypothetical single day of RT }}{\text { Elapsed days from start of RT to death }}
$$

Finally, we calculated the radiation therapy-free life gained (RTFLG), representing the percentage of a patient's life which could have been spent outside of the hospital setting had they instead received single fraction RT:

$$
\begin{aligned}
\operatorname{RTFLG}(\%) & =\frac{\text { Elapsed days of RT }- \text { Hypothetical single day of RT }}{\text { Elapsed days from start of RT to death }} \\
& =P R L S R T-H_{\text {PRLSRT }}
\end{aligned}
$$

Descriptive analysis of practice patterns including most common dose-fractionation schemes, sites of metastasis and various other demographic and patient related characteristics were performed. To calculate the number of incomplete RT courses, dose per fraction was calculated and compared to standard dose regimens: 4 Gy/fraction (20-24 Gy in 5-6 fractions), 3 Gy/fraction (30 Gy in 10 fractions), 2.5 Gy/ fractions (35-37.5 Gy in 14-15 fractions), and 2 Gy/fraction (40 Gy in 20 fractions). Patients with a standard fraction size as defined above, but less than the appropriate number of fractions for a standard regimen we deemed to have an incomplete course. For most analysis, patients were stratified into four treatment groups based on number of fractions received: 1, 2-5, 6-10, and greater than 10 . 


\section{Statistical analysis}

Univariate comparisons were made using Chi-Square, ANOVA, or $t$-tests. Kaplan-Meier Curves and logrank test were used to examine survival outcomes and Cox proportional hazards models were used to identify predictors of survival. Overall survival (OS) was calculated from the start of RT until death or last follow-up. Hazards ratio (HR), and $95 \%$ confidence intervals (CIs) were reported for the Cox regression analysis. Alpha was established at 0.05 for all tests and $\mathrm{P}<0.05$ was considered significant. Statistical analyses were performed using SPSS version 24.0 (IBM Corp., New York, NY, USA).

\section{Results}

A total of 1,331 patients received palliative RT for BMs from HCC. For the entire cohort, median patient age was 61 years. The vast majority of patients were male (86.3\%) and Caucasian $(74.9 \%)$. Patient characteristics of the entire cohort as well as subdivided by fractionation group (1 Fx, 2-5 Fx, 6-10 Fx, >10 Fx) are outlined in Table 1. Most common sites of treatment were the spine $(62.3 \%)$, hip/ pelvis $(18.5 \%)$, and shoulder/extremity (10.5\%). Most patients received $30 \mathrm{~Gy}$ in 10 fractions $(36.3 \%)$. The ten most common dose-fraction schemes are shown in Figure $1 \mathrm{~A}$ and annual usage trends for RT separated by fraction group are shown in Figure 1B. Over time there appeared to be a trend, albeit small, toward decreased utilization of longer $(>10 \mathrm{Fx})$ multifraction regimens and increased utilization of single fraction and hypofractionated (defined as 5 or fewer fractions) regimens. Peak annual usage of single fraction palliative RT was $5.5 \%$. Survival after radiation within this cohort was very poor with median OS, 1- and 2-year OS of 3.3 months, $17.3 \%$ and $7.8 \%$, respectively. Survival plots for the entire cohort as well as stratified by fraction group are shown in Figure 2. Following the start of RT, 21\%, $45.8 \%$ and $66.6 \%$ of patients died within 1,3 and 6 months, respectively.

Forty-nine $(3.7 \%)$ patients received single fraction palliative RT compared to 198 (14.9\%), 628 (47.2\%), and 456 (34.3\%) of patients who received 2-5, 6-10, and >10 Fx, respectively. Of those who received a single treatment, 24 patients $(50 \%$ of single fractions cohort and $1.8 \%$ of the entire cohort) were treated with stereotactic radiosurgery. Overall mean and median PRLSRT were $26.4 \%$ and $15.4 \%$, respectively. Mean and median PRLSRT were $8.9 \%$ and $3.0 \%$ for $1 \mathrm{Fx}, 32.9 \%$ and $24.3 \%$ for $2-5 \mathrm{Fx}, 27.2 \%$ and $15.9 \%$ for $6-10 \mathrm{Fx}$, and $24.1 \%$ and $14.4 \%$ for $>10 \mathrm{Fx}$ (Table 2). Mean and median PRLSRT was significantly different in all fraction groups when compared individually to the single fraction group (all $\mathrm{P}<0.001$ ). Distributions of PRLSRT as a function of fraction group are shown in Figures 3,4. The majority of patients had PRLSRT $\leq 25 \%$ regardless of fraction group. There were no patients in the 1 Fx group who had PRLSRT $>75 \%$. Nearly all (248/249 or $99.6 \%$ ) patients with a PRLSRT $\geq 50 \%$ received multifraction regimens.

The percentage of patients with incomplete courses increased as the dose per fraction decreased and the number of fractions increased. The percent incomplete course was $17.6 \%$ for 4 Gy per fraction, $21.7 \%$ for 3 Gy/fraction, $24 \%$ for $2.5 \mathrm{~Gy} /$ fraction, and $34 \%$ for $2 \mathrm{~Gy} /$ fraction. On multivariate analysis, increasing age, elevated AFP, shorter number of radiation fractions, spine metastasis, not receiving chemotherapy, and palliative RT less than 30 days after diagnosis was associated with shorter survival (Table 3).

In our exploratory analysis, mean $\mathrm{H}_{\text {PRLSRT }}$ compared to mean PRLSRT were $7.2 \%$ and $32.9 \%$ for $2-5 \mathrm{Fx}, 2.2 \%$ and $27.2 \%$ for $6-10 \mathrm{Fx}$, and $1.1 \%$ and $24.1 \%$ for $>10 \mathrm{Fx}$ (Table 2) and was statistically significant for all groups $(\mathrm{P}<0.001)$. Distributions of $\mathrm{H}_{\text {PRLSRT }}$ as a function of fraction group are shown in Figure 4. For the subset of the cohort receiving multiple fraction $\mathrm{RT}$, the mean and median RTFLG were $24.5 \%$ and $14.8 \%$, respectively.

\section{Discussion}

The diagnosis of HCC with BMs confers a grim prognosis. Median survival in this cohort was 3.3 months with a $17.3 \% 1$-year and a $7.8 \% 2$-year OS. These findings are consistent with the existing literature rates of 1 - and 2-year OS of $18.1 \%$ and $6.3 \%$ reported by Choi et al. (23). Given the short survival time and the equivalence of single and multifraction regimens for the treatment of BMs, efforts should be made to reduce palliative RT duration to maximize patient comfort, quality of life and reduce time spent receiving RT. Numerous studies have shown that there is no difference in pain response rates, time to improvement in pain, time to complete pain relief or duration of pain relief when comparing single and multifraction palliative RT for BMs (13-20,24). Despite those findings, this study demonstrates a significant underutilization of single fraction palliative RT in the treatment of BMs from HCC. Only $3.7 \%$ of patients received single fraction therapy, of which about half received SRS (1.8\% of total population), and a 
Table 1 Patient characteristics

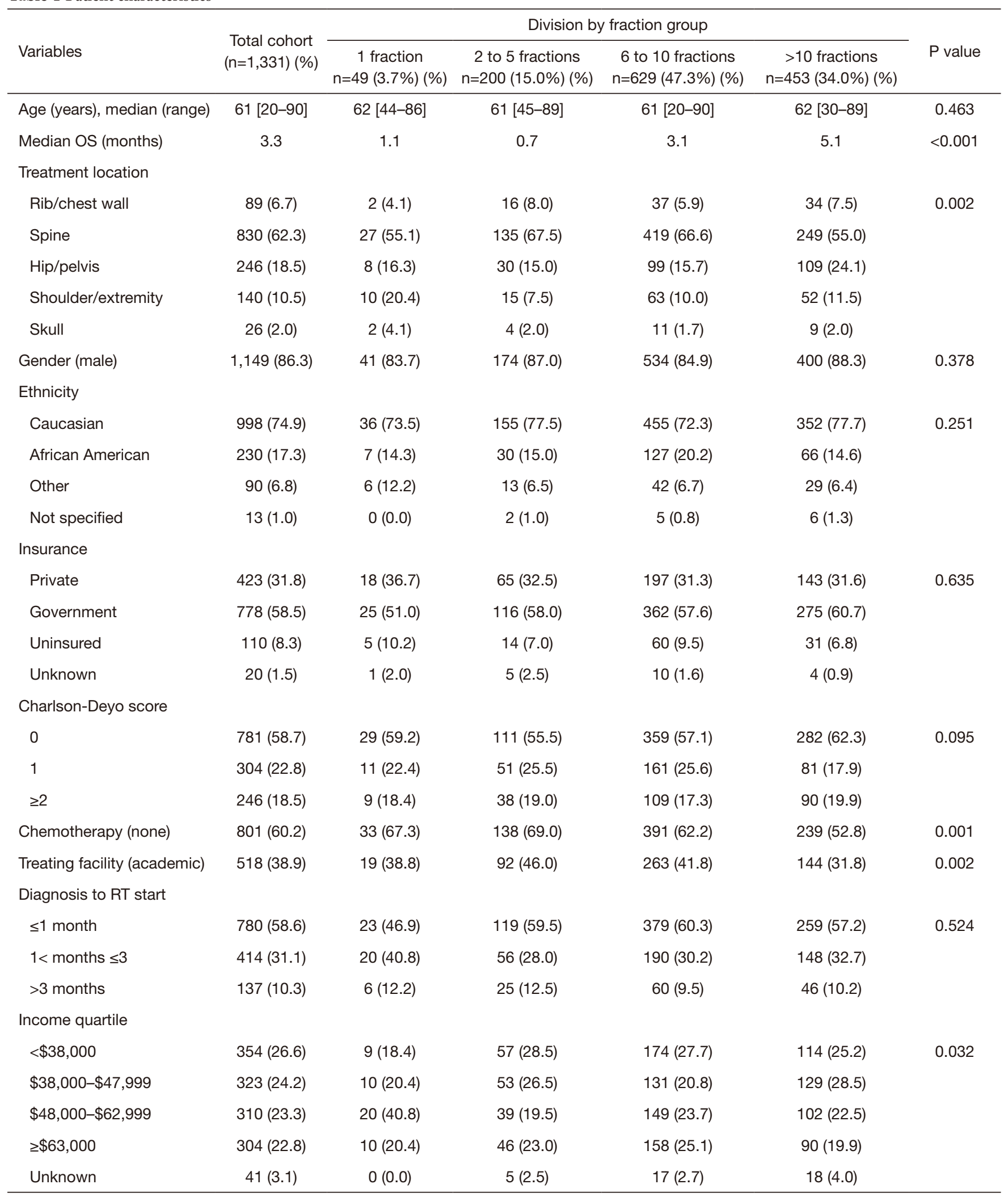

OS, overall survival; RT, radiation therapy. 

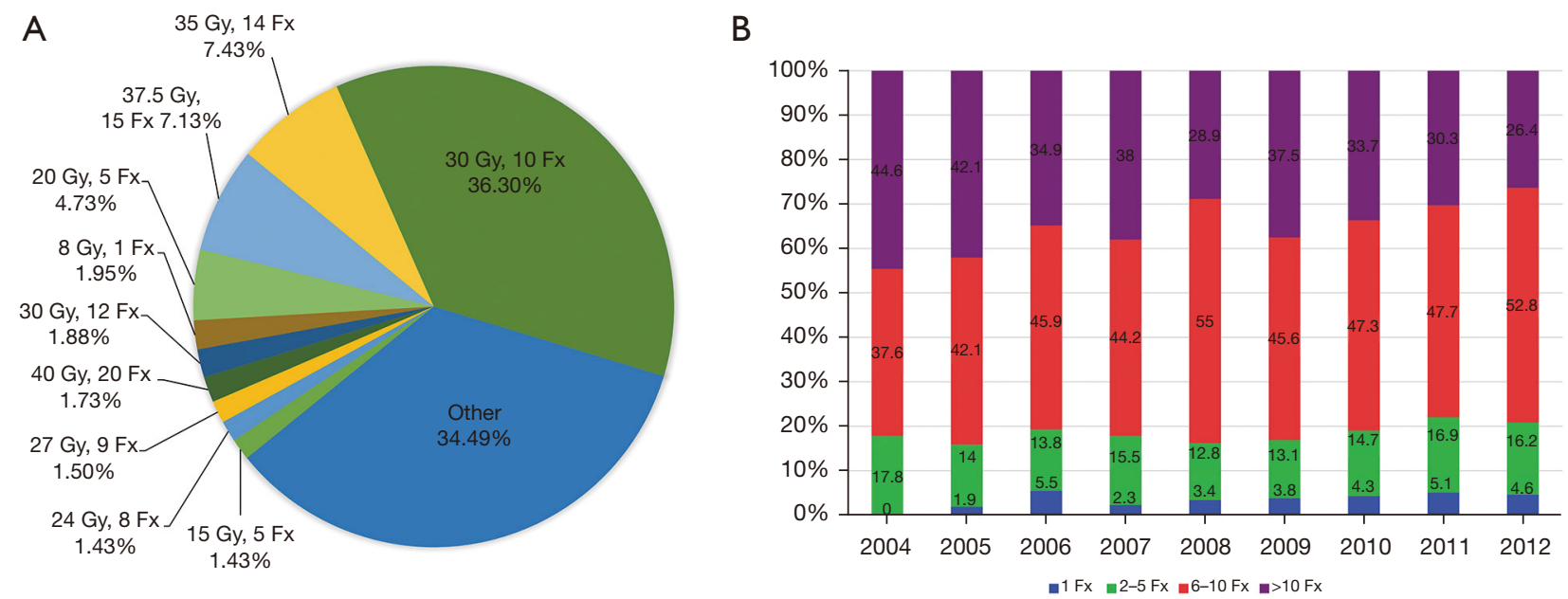

Figure 1 Distribution of fractionation schemes and trends in utilization. (A) Ten most common dose-fractionation schemes; (B) annual utilization trends of palliative RT by fraction group. Gy, gray; Fx, fraction; RT, radiation therapy.
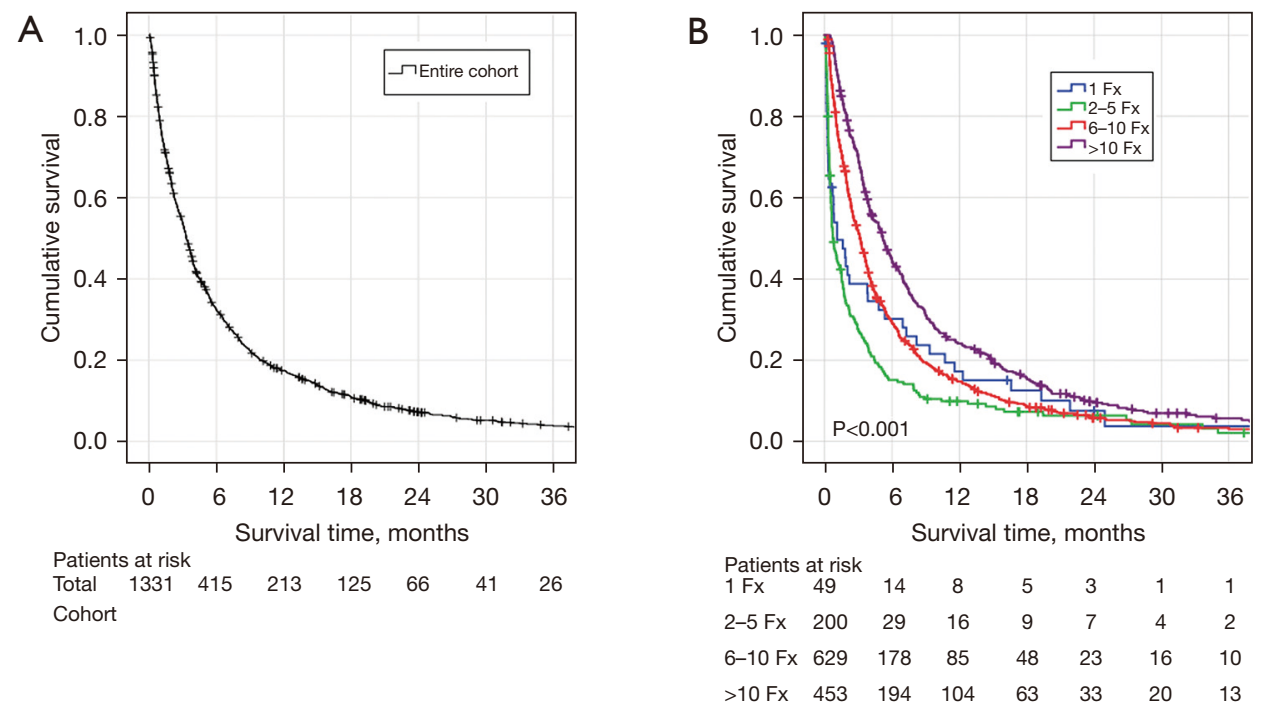

Figure 2 Kaplan-Meier survival curves of overall survival. (A) The entire cohort and (B) stratified by fraction groups. Fx, fraction.

substantial $34 \%$ of patients received $>10 \mathrm{Fx}$.

In this study the PRLSRT metric was used to characterize how the choice of dose-fraction scheme affects how patients spend their remaining life. Patients receiving single fraction RT had a mean $8.9 \%$ PRLSRT, compared to $32.9 \%, 27.5 \%$, and $24.1 \%$ for patients receiving $2-5,5-10$, and $>10 \mathrm{Fx}$, respectively. Patients receiving multifraction RT spend a significantly higher proportion of their final days receiving RT. Likewise, longer courses increase the proportion of incomplete courses of RT. Approximately one-third of patients prescribed multifraction regimens did not complete their prescribed RT course, which could suggest that the burden of time, energy, and resources required to complete multifraction courses outweighed the potential benefits of completing treatment for many patients. This burden likewise potentially eroded the anticipated benefits of palliative RT.

It was hypothesized that PRLSRT would increase proportionally with number of fractions received, but that trend was not observed in these data. The highest PRLSRT corresponded to the 2-5 Fx group, which also had the lowest median survival at 0.72 months while the 
Table 2 PRLSRT, $\mathrm{H}_{\text {PRLSRT }}$, and RTFLG metrics stratified by fraction group

\begin{tabular}{|c|c|c|c|c|c|}
\hline Variables & Total cohort $(n=1,331)$ & \multicolumn{4}{|c|}{ Division by fraction group } \\
\hline Mean PRLSRT (\%) & 26.4 & 8.9 & 32.9 & 27.2 & 24.1 \\
\hline Median PRLSRT (\%) & 15.4 & 3.0 & 24.3 & 15.9 & 14.4 \\
\hline Mean $\mathrm{H}_{\text {PRLSRT }}(\%)$ & 2.59 & N/A & 7.2 & 2.2 & 1.1 \\
\hline Mean RTFLG (\%) & 24.5 & $\mathrm{~N} / \mathrm{A}$ & 25.9 & 25.1 & 23.0 \\
\hline Median RTFLG (\%) & 14.8 & $\mathrm{~N} / \mathrm{A}$ & 20.1 & 14.8 & 13.8 \\
\hline
\end{tabular}

PRLSRT, percentage of remaining life spent receiving radiation therapy; $\mathrm{H}_{\mathrm{PRLSRT}}$, hypothetical percentage of remaining life spent receiving radiation therapy; RTFLG, radiation therapy-free life gained; N/A, not applicable.

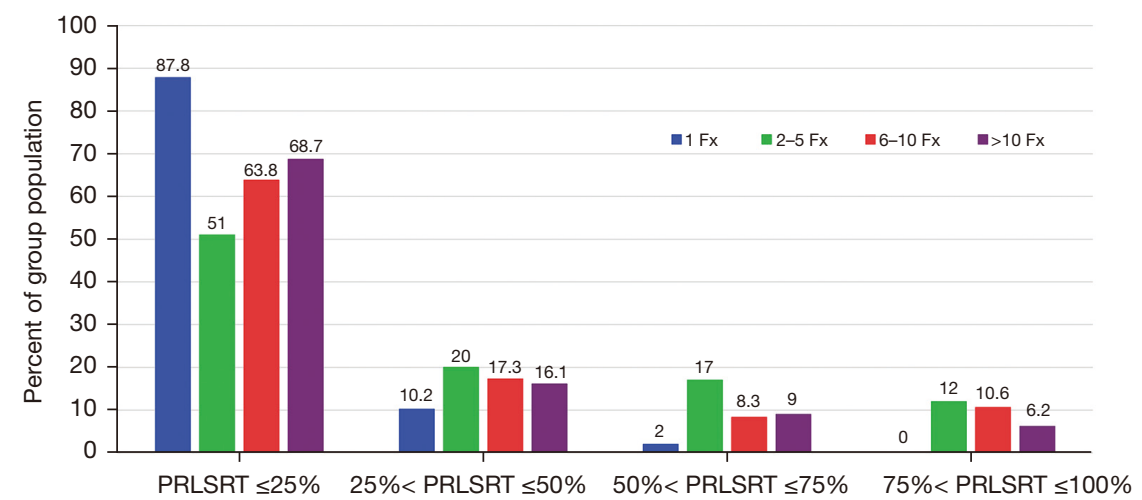

Figure 3 Distribution of PRLSRT by fraction group and PRLSRT quartile. PRLSRT, percentage of remaining life spent receiving radiation therapy; Fx, fraction.

$>10 \mathrm{Fx}$ group had the highest median OS at 5.1 months. It is possible that the increased PRLSRT observed in the 2-5 fraction group reflects both a consideration regarding prognosis when selecting fractionation schema and a possible reluctance for single fraction treatments. Instead of receiving a single fraction, patients with the worse prognosis were given a 2-5 fraction regiment because providers may have been more comfortable and experienced with these regimens, which resulted in a higher PRSLRT and shorter survival in this group (25). Clinicians should choose treatment regimens that reflect the patient's prognosis and match the goals of treatment with the goals of care. Given the poor survival in this cohort and in the literature, increased consideration should be given to single fraction palliative RT. If those in the 2-5, 6-10 and >10 Fx groups had received just single fraction $\mathrm{RT}$, without compromising outcome the mean PRLSRT would have improved from
$32.9 \%, 27.2 \%$, and $24.1 \%$ to $7.2 \%, 2.2 \%$, and $1.1 \%$, respectively. Patients also would have gained a mean $25.9 \%$, $25.1 \%$, and $23.0 \%$, respectively, of their remaining life back outside of the hospital setting.

There are a number of reasons why radiation oncologists are reluctant to use single fraction regimens. The most important of which is likely the higher reported retreatment rate after single fraction treatment. Retreatment after single fractions has been previously shown to be in upwards of $20-30 \%$ for single fraction RT compared to $7.4 \%$ in the multiple fraction group with retreatment likelihood 3.44-fold higher (95\% CI: 2.67 to 4.43 ) $(18,24,26)$. Time to retreatment differs with average of 14 weeks (single fraction) versus 23 weeks (multifraction) (27). Additionally the Bone Pain Trail Working group reported retreatment probability at 3 and 6 months was roughly $10 \%$ and $20 \%$ for single fraction and $5 \%$ and $10 \%$ for multi-fraction treatments (24). 
A
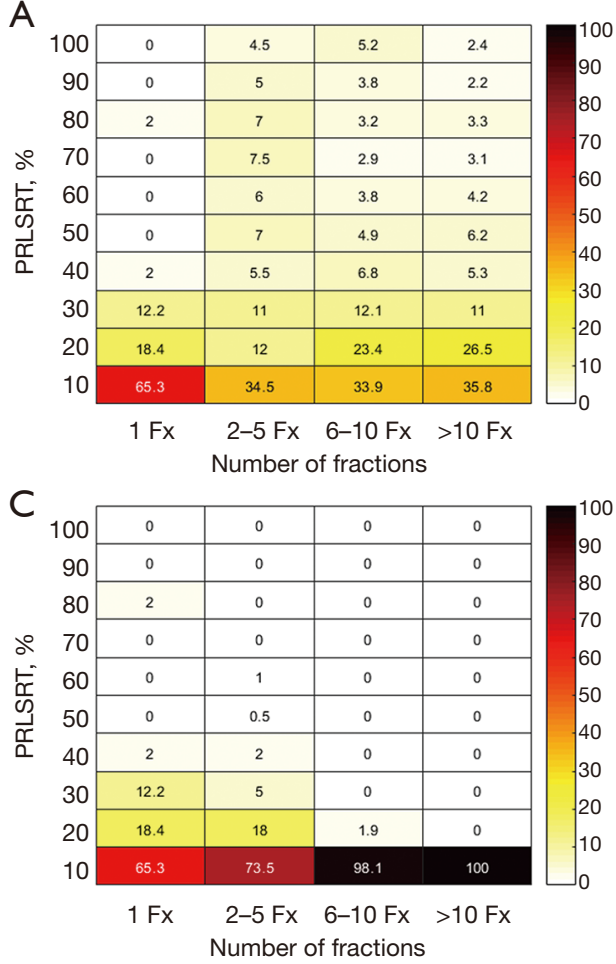

B
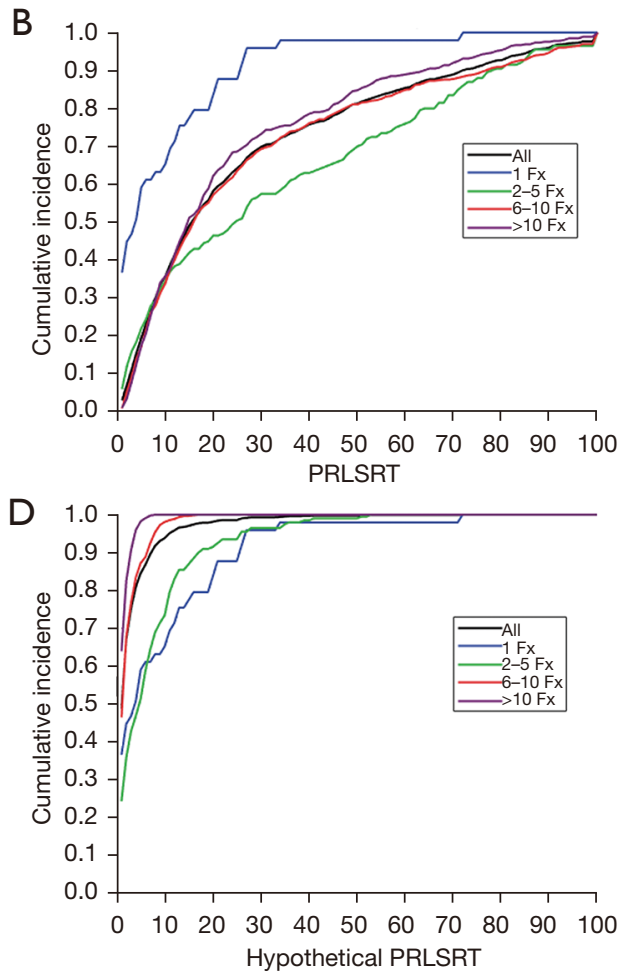

Figure 4 Heat maps and cumulative PRLSRT graphs. (A) and (C) are heat map distributions of PRLSRT tertials by fraction group (A is actual distribution, $\mathrm{C}$ is the hypothetical PRLSRT distribution based on all patients receiving single fraction). Y-axis is the PRLSRT tertials, $\mathrm{X}$-axis is the fraction groups. (B) and (D) are cumulative incidence graphs depicting PRLSRT distributions by fraction group (B is actual distribution, $\mathrm{D}$ is the hypothetical PRLSRT distribution). $\mathrm{Y}$-axis is the cumulative incidence in percentages, $\mathrm{X}$-axis is the PRLSRT percentage. PRLSRT, percentage of remaining life spent receiving radiation therapy; Fx, fraction.

However, there is no difference in time to first increase in pain (24) and pain scores prior to retreatment were lower or no different in the single fraction group (27). These data suggest that physician bias and increased willingness to give repeat treatment following single dose RT, rather than actual necessity, explains reported differences in retreatment rates $(16,24,27)$. Determination regarding radiation treatment schema should be considered within the context of the underlying malignancy. Most patients with HCC requiring RT for osseous metastases have a poor overall poor prognosis and anticipated survival of only a few months, so the retreatment rates are likely irrelevant since most patients will not live long enough. Considering the prognosis and time to retreatment should help reduce the reluctancy for using single fraction treatment in this cohort, except for those small handful of patients with potential for longer survival.

While most RT is given in the outpatient setting, it is of utmost importance to consider the patient's wishes with their remaining time and the socioeconomic implications of RT when selecting the dose-fraction scheme. Multifraction RT often requires daily trips to the radiation center that may be a significant distance from home (18). This may create a significant hardship, especially in patients with poor performance status. Significant time, energy, strength, and other resources are required from the patients and their caregivers to complete multi-fraction regimens and often, patients fail to complete the planned course of treatment. The number of incomplete courses rose as the fractional dose decreased and the number of treatments increased. When RT courses are stopped early, the anticipated palliative benefits may not be realized.

This study identifies several factors associated with decreased survival for patients with HCC who received palliative radiation for BMs: elevated AFP, spine vs nonspine osseous metastasis, age, the use of chemotherapy, and time from diagnosis to receiving palliative RT. Many of these factors have also been reported by others $(9,23,28-30)$. 
Table 3 Univariate and multivariate analysis of overall survival after palliative RT

\begin{tabular}{|c|c|c|c|c|c|c|}
\hline Category & \multicolumn{3}{|c|}{ Univariate analysis } & \multicolumn{3}{|c|}{ Multivariate analysis } \\
\hline Age continuous variable & 1.007 & $1.002-1.013$ & 0.007 & 1.007 & $1.001-1.012$ & 0.017 \\
\hline Sex [male (Ref) vs. female] & 1.091 & $0.924-1.288$ & 0.305 & & & \\
\hline \multicolumn{7}{|l|}{ Charlson-Deyo score } \\
\hline 1 & 1.161 & $1.011-1.333$ & 0.034 & 1.092 & $0.948-1.259$ & 0.222 \\
\hline 2 & 1.119 & $0.960-1.303$ & 0.150 & 1.132 & $0.969-1.322$ & 0.119 \\
\hline \multicolumn{7}{|l|}{ Treating facility } \\
\hline Academic & (Ref) & (Ref) & (Ref) & & & \\
\hline Private & (Ref) & (Ref) & (Ref) & (Ref) & (Ref) & (Ref) \\
\hline Government & 1.132 & $0.999-1.284$ & 0.052 & 0.100 & $0.964-1.255$ & 0.156 \\
\hline Uninsured/unknown & 1.237 & $0.992-1.542$ & 0.058 & 1.092 & $0.874-1.368$ & 0.435 \\
\hline \multicolumn{7}{|l|}{ Alpha-Feto protein } \\
\hline Normal & (Ref) & (Ref) & (Ref) & (Ref) & (Ref) & (Ref) \\
\hline Elevated & 1.337 & $1.098-1.627$ & 0.004 & 1.282 & $1.050-1.565$ & 0.015 \\
\hline Unknown & 1.235 & $1.004-1.518$ & 0.045 & 1.247 & $1.011-1.537$ & 0.039 \\
\hline \multicolumn{7}{|l|}{ Number of fractions } \\
\hline$\leq 30$ days & 1.378 & $1.131-1.679$ & 0.001 & 1.286 & $1.052-1.572$ & 0.014 \\
\hline$>30$ to $\leq 90$ days & 1.189 & $0.964-1.465$ & 0.106 & 1.218 & $1.218-1.505$ & 0.068 \\
\hline$>90$ days & (Ref) & (Ref) & (Ref) & (Ref) & (Ref) & (Ref) \\
\hline \multicolumn{7}{|l|}{ Osseous site } \\
\hline Other bone site & (Ref) & (Ref) & (Ref) & (Ref) & (Ref) & (Ref) \\
\hline Spine & 1.404 & $1.249-1.579$ & $<0.001$ & 1.289 & $1.142-1.455$ & $<0.001$ \\
\hline \multicolumn{7}{|l|}{ Chemotherapy } \\
\hline Yes & (Ref) & (Ref) & (Ref) & (Ref) & (Ref) & (Ref) \\
\hline No & 1.702 & $1.514-1.912$ & $<0.001$ & 1.701 & $1.509-1.918$ & $<0.001$ \\
\hline
\end{tabular}

$\mathrm{RT}$, radiation therapy; Ref, reference. 
Performance status remains one of the most important drivers of prognosis (31-34). In this population of patients with a generally poor overall prognosis who may have been underrepresented in the randomized trials of fractionation for BM, it may be important to differentiate those with the potential for longer survival as several retrospective studies have reported associations between increased radiation dose and improved response duration (28,35), possible improved complete pain response rates $(23,30,35)$, and higher radiographic response rates (35). Since there was little evidence for improved initial pain response, this difference will be most important for those with the longest life expectancy. The only randomized trial of palliative RT for BMs from HCC showed no difference in survival or toxicity based on the number of fractions (20-30 vs. 7-10 fractions), but reported a shorter time to response with the more hypofractionated regimen and a longer time to treatment failure in the more fractionated group (36). Any benefits of increased total radiation dose and longer treatment duration need to be weighed against the potential impact on the percent remaining life spent receiving RT and the burden of extended radiation treatment regimens.

There were several limitations in this study. Like most large database retrospective studies, the population of patients who received 1 fraction was relatively low. Additionally, there was no data regarding pain response, quality of life information, retreatment, or the extent of systemic disease at time of RT treatment, which would have provided a more detailed analysis of response and outcomes. The PRLSRT metric is strongly influenced by short survival and radiation duration. Since patients in the present study had poor survival outcomes (median survival after radiation of about 3 months), some may question the generalizability of the study results and the PRLSRT metric, but this must be taken in context. It is acknowledged that several studies of HCC patients reported longer OS outcomes with median survival of 5-11 months (37-40), but these studies typically calculated survival from the diagnosis of BMs instead of the start of RT, included only $50-60 \%$ of patients who required palliative RT, and treated patients in a more uniform manner with high proportions receiving systemic treatment with chemotherapy and bisphosphonates. Given these factors, the differences in the reported survival rates are not surprising, since it could be months between the diagnosis of BMs and progression of the lesions to become symptomatic enough to require intervention with radiation. Additionally due to the rarity of the diagnosis, any center reporting significant numbers of patients with HCC BMs are likely centers of excellence with significant experiences managing metastatic HCC, especially compared to the patients in the current study, who were treated at every kind of center. Despite these limitations, the current study gives unique insight into the practice patterns and outcomes after palliative RT for BMs from HCC and is valuable because it is one of the only studies to report the survival from the time of RT, which is crucial for determining prognosis and radiation fractionation.

In conclusion, in this cohort of patients with BMs from HCC, those who receive multifraction palliative regimens have a significantly increased PRLSRT when compared to single fraction RT. Despite equivalence in pain control between single and multi-fraction regimens, there remains a prominent underutilization of single fraction palliative treatments. In the palliative treatment of painful BMs from any malignancy, and particularly those with a poor prognosis such as metastatic HCC, single fraction RT should be utilized to reduce time spent receiving treatment and the number of incomplete courses.

\section{Acknowledgments}

Funding: None.

\section{Footnote}

Reporting Checklist: The authors have completed the STROBE reporting checklist. Available at https://apm. amegroups.com/article/view/10.21037/apm-21-2657/rc

Peer Review File: Available at https://apm.amegroups.com/ article/view/10.21037/apm-21-2657/prf

Conflicts of Interest: All authors have completed the ICMJE uniform disclosure form (available at https://apm. amegroups.com/article/view/10.21037/apm-21-2657/coif). CAJ serves as a co-chair for the Palliative Radiotherapy Subcommittee on the Editorial Board of the Annals of Palliative Medicine from July 2021 to June 2023. The other authors have no conflicts of interest to declare.

Ethical Statement: The authors are accountable for all aspects of the work in ensuring that questions related to the accuracy or integrity of any part of the work are appropriately investigated and resolved. The study was conducted in accordance with the Declaration of Helsinki (as revised in 2013). 
Open Access Statement: This is an Open Access article distributed in accordance with the Creative Commons Attribution-NonCommercial-NoDerivs 4.0 International License (CC BY-NC-ND 4.0), which permits the noncommercial replication and distribution of the article with the strict proviso that no changes or edits are made and the original work is properly cited (including links to both the formal publication through the relevant DOI and the license). See: https://creativecommons.org/licenses/by-nc-nd/4.0/.

\section{References}

1. Kane CM, Hoskin P, Bennett MI. Cancer induced bone pain. BMJ 2015;350:h315.

2. Falk S, Dickenson AH. Pain and nociception: mechanisms of cancer-induced bone pain. J Clin Oncol 2014;32:1647-54.

3. Zhu XC, Zhang JL, Ge CT, et al. Advances in cancer pain from bone metastasis. Drug Des Devel Ther 2015;9:4239-45.

4. Longo V, Brunetti O, D'Oronzo S, et al. Bone metastases in hepatocellular carcinoma: an emerging issue. Cancer Metastasis Rev 2014;33:333-42.

5. Reale C, Turkiewicz AM, Reale CA. Antalgic treatment of pain associated with bone metastases. Crit Rev Oncol Hematol 2001;37:1-11.

6. Noone AM, Howlader N, Krapcho M, et al. SEER Cancer Statistics Review, 1975-2015, National Cancer Institute. Bethesda, MD. Based on November 2017 SEER data submission, posted to the SEER web site, April 2018. Available online: https://seer.cancer.gov/csr/1975_2015/

7. Llovet JM, Burroughs A, Bruix J. Hepatocellular carcinoma. Lancet 2003;362:1907-17.

8. Harding JJ, Abu-Zeinah G, Chou JF, et al. Frequency, Morbidity, and Mortality of Bone Metastases in Advanced Hepatocellular Carcinoma. J Natl Compr Canc Netw 2018;16:50-8.

9. Hayashi S, Tanaka H, Hoshi H. Palliative external-beam radiotherapy for bone metastases from hepatocellular carcinoma. World J Hepatol 2014;6:923-9.

10. Seong J, Koom WS, Park HC. Radiotherapy for painful bone metastases from hepatocellular carcinoma. Liver Int 2005;25:261-5.

11. Roca EL, Okazaki N, Okada S, et al. Radiotherapy for bone metastases of hepatocellular carcinoma. Jpn J Clin Oncol 1992;22:113-6.

12. Tong D, Gillick L, Hendrickson FR. The palliation of symptomatic osseous metastases final results of the study by the radiation therapy oncology group. Cancer 1982;50:893-9.

13. Chow E, Harris K, Fan G, et al. Palliative radiotherapy trials for bone metastases: a systematic review. J Clin Oncol 2007;25:1423-36.

14. Sze WM, Shelley MD, Held I, et al. Palliation of metastatic bone pain: single fraction versus multifraction radiotherapy--a systematic review of randomised trials. Clin Oncol (R Coll Radiol) 2003;15:345-52.

15. Wu JS, Wong R, Johnston M, et al. Meta-analysis of dose-fractionation radiotherapy trials for the palliation of painful bone metastases. Int J Radiat Oncol Biol Phys 2003;55:594-605.

16. Hartsell WF, Scott CB, Bruner DW, et al. Randomized trial of short- versus long-course radiotherapy for palliation of painful bone metastases. J Natl Cancer Inst 2005;97:798-804.

17. Chow E, Zeng L, Salvo N, et al. Update on the systematic review of palliative radiotherapy trials for bone metastases. Clin Oncol (R Coll Radiol) 2012;24:112-24.

18. Sze WM, Shelley M, Held I, et al. Palliation of metastatic bone pain: single fraction versus multifraction radiotherapy - a systematic review of the randomised trials. Cochrane Database Syst Rev 2004;2002:CD004721.

19. Chow R, Hoskin P, Hollenberg D, et al. Efficacy of single fraction conventional radiation therapy for painful uncomplicated bone metastases: a systematic review and meta-analysis. Ann Palliat Med 2017;6:125-42.

20. Chow R, Hoskin P, Schild SE, et al. Single vs multiple fraction palliative radiation therapy for bone metastases: Cumulative meta-analysis. Radiother Oncol 2019;141:56-61.

21. Lutz S, Balboni T, Jones J, et al. Palliative radiation therapy for bone metastases: Update of an ASTRO Evidence-Based Guideline. Pract Radiat Oncol 2017;7:4-12.

22. American Society for Radiation Oncology [Internet]. Ten Things Physicians and Patients Should Question. Choosing Wisely 2015 Available online: https://www. choosingwisely.org/societies/american-society-forradiation-oncology/, assessed on 6/24/2021.

23. Choi C, Seong J. Predictive factors of palliative radiotherapy response and survival in patients with spinal metastases from hepatocellular carcinoma. Gut Liver 2015;9:94-102.

24. 8 Gy single fraction radiotherapy for the treatment of metastatic skeletal pain: randomised comparison with a multifraction schedule over 12 months of patient follow- 
up. Bone Pain Trial Working Party. Radiother Oncol 1999;52:111-21.

25. Rutter CE, Yu JB, Wilson LD, et al. Assessment of national practice for palliative radiation therapy for bone metastases suggests marked underutilization of singlefraction regimens in the United States. Int J Radiat Oncol Biol Phys 2015;91:548-55.

26. Foro Arnalot P, Fontanals AV, Galcerán JC, et al. Randomized clinical trial with two palliative radiotherapy regimens in painful bone metastases: 30 Gy in 10 fractions compared with 8 Gy in single fraction. Radiother Oncol 2008;89:150-5.

27. Steenland E, Leer JW, van Houwelingen $\mathrm{H}$, et al. The effect of a single fraction compared to multiple fractions on painful bone metastases: a global analysis of the Dutch Bone Metastasis Study. Radiother Oncol 1999;52:101-9.

28. Hayashi S, Tanaka H, Hoshi H. External beam radiotherapy for painful bone metastases from hepatocellular carcinoma: multiple fractions compared with an 8-Gy single fraction. Nagoya J Med Sci 2014;76:91-9.

29. Natsuizaka M, Omura T, Akaike T, et al. Clinical features of hepatocellular carcinoma with extrahepatic metastases. J Gastroenterol Hepatol 2005;20:1781-7.

30. He J, Zeng ZC, Tang ZY, et al. Clinical features and prognostic factors in patients with bone metastases from hepatocellular carcinoma receiving external beam radiotherapy. Cancer 2009;115:2710-20.

31. Katagiri H, Takahashi M, Wakai K, et al. Prognostic factors and a scoring system for patients with skeletal metastasis. J Bone Joint Surg Br 2005;87:698-703.

32. Kubota H, Soejima T, Sulaiman NS, et al. Predicting the survival of patients with bone metastases treated with

Cite this article as: Schmid RK, Johnstone CA, Robbins JR. Palliative radiation for bone metastases from hepatocellular carcinoma: practice patterns and the amount of remaining life spent receiving treatment. Ann Palliat Med 2022;11(6):1900-1910. doi: 10.21037/apm-21-2657 radiation therapy: a validation study of the Katagiri scoring system. Radiat Oncol 2019;14:13.

33. Krishnan MS, Epstein-Peterson Z, Chen YH, et al. Predicting life expectancy in patients with metastatic cancer receiving palliative radiotherapy: the TEACHH model. Cancer 2014;120:134-41.

34. Chow E, Harth T, Hruby G, et al. How accurate are physicians' clinical predictions of survival and the available prognostic tools in estimating survival times in terminally ill cancer patients? A systematic review. Clin Oncol (R Coll Radiol) 2001;13:209-18.

35. Jung IH, Yoon SM, Kwak J, et al. High-dose radiotherapy is associated with better local control of bone metastasis from hepatocellular carcinoma. Oncotarget 2017;8:15182-92.

36. He J, Shi S, Ye L, et al. A randomized trial of conventional fraction versus hypofraction radiotherapy for bone metastases from hepatocellular carcinoma. J Cancer 2019;10:4031-7.

37. Seo HJ, Kim GM, Kim JH, et al. ${ }^{18}$ F-FDG PET/CT in hepatocellular carcinoma: detection of bone metastasis and prediction of prognosis. Nucl Med Commun 2015;36:226-33.

38. Honda Y, Aikata H, Honda F, et al. Clinical outcome and prognostic factors in hepatocellular carcinoma patients with bone metastases medicated with zoledronic acid. Hepatol Res 2017;47:1053-60.

39. $\mathrm{Lu} \mathrm{Y}, \mathrm{Hu} \mathrm{JG}$, Lin $\mathrm{XJ}$, et al. Bone metastases from hepatocellular carcinoma: clinical features and prognostic factors. Hepatobiliary Pancreat Dis Int 2017;16:499-505.

40. Santini D, Pantano F, Riccardi F, et al. Natural history of malignant bone disease in hepatocellular carcinoma: final results of a multicenter bone metastasis survey. PLoS One 2014;9:e105268. 